\title{
MAP4K4 Expression is Selectively Upregulated and Increases Cell Invasion in Pancreatic Ductal Adenocarcinoma
}

\author{
Simona O. Dima ${ }^{1}$, Mihaela Chivu-Economescu², Raluca Purnichescu-Purtan ${ }^{3}$, Anca Nastase $^{1}$, \\ Nicolae Bacalbaşa ${ }^{4}$, Raluca Florea ${ }^{1}$, Coralia Bleotu ${ }^{2}$, Carmen Diaconu ${ }^{2}$, Dan G. Duda ${ }^{5}$, Vlad Herlea ${ }^{1,6}$, \\ Irinel Popescu ${ }^{1}$
}

${ }^{1}$ Center of Digestive Disease and Liver Transplantation, Fundeni Clinical Institute, Bucharest, Romania

${ }^{2}$ Stefan S. Nicolau Institute of Virology, Bucharest, Romania

${ }^{3}$ Department of Mathematics, Faculty of Applied Sciences, Polytechnic University of Bucharest, Romania

${ }^{4}$ Carol Davila University of Medicine and Pharmacy, Bucharest , Romania

${ }^{5}$ Department of Radiation Oncology, Massachusetts General Hospital, Harvard Medical School, Boston, USA

${ }^{6}$ University Titu Maiorescu, Faculty of Medicine, Bucharest, Romania
Corresponding author: Irinel Popescu, MD, PhD, FACS

Center of Digestive Disease and Liver Transplantation Fundeni Clinical Institute Sos. Fundeni 258, Sector 2, Bucharest 022328, Romania E-mail: irinel.popescu220@gmail.com

\section{ABSTRACT}

The objective of this study was to determine whether the mitogen-activated protein kinase kinase kinase kinase 4 (MAP4K4) expression can differentiate pancreatic ductal adenocarcinoma (PDA) from chronic pancreatitis (CP) and to analyze its biological and clinical significance in PDA. We have previously found by gene array analysis that MAP4K4 is overexpressed in PDA tissues. Here, we measured MAP4K4 gene and protein expression in 58 PDA and 9 CP surgical specimens using RT-PCR and immunohistochemistry, and analyzed their association with clinical outcomes. MAP4K4 mRNA expression was significantly higher in PDA versus CP tissues (Mann Whitney test, $p<0.003$ ), and correlated with TNM stage (Kruskal-Wallis test, $p \leq 0.026$ ). MAP4K4 protein expression was significantly correlated with tumor grade (Spearman's Rho $=0.449, p \leq 0.01)$, and tended to associate with shorter overall survival $(p \leq 0.076$, log-rank test). In conclusion, our data indicate that the level of MAP4K4 expression directly correlates with PDA progression. Thus these data suggest that MAP4K4 may be a biomarker and potentially a target for therapy in PDA.

Key words: mitogen-activated protein kinase kinase kinase kinase 4 (MAP4K4), pancreatic cancer

\section{INTRODUCTION}

Pancreatic ductal adenocarcinoma (PDA) remains a major health problem. Yearly, PDA incidence closely matches its mortality, highlighting the limited efficacy of existing treatment options $(1,2)$. The prognosis of pancreatic cancer is extremely poor, with an overall 5 -year survival of less than $5 \%$, mainly because 
of the late onset of disease-specific symptoms and a shortage of good targets and biomarkers for the disease (3).

By combining gene expression analyses of wholetissue and microdissected PDA, we previously identified the mitogen-activated protein kinase kinase kinase kinase 4 (MAP4K4) as one of the gene specifically overexpressed in PDA (4). The MAP4K4 gene encodes for the MAP4K4 protein, a member of the mitogenactivated protein kinases family (MAPK). MAPK signaling pathways are commonly activated through phosphorylation cascades downstream growth factor receptors and promote cell proliferation and survival (5-7). The MAP4K4 gene encodes an upstream activator of the JNK pathway, which is involved in cellular responses to stress and cell apoptosis $(8,9)$. Moreover the function of MAP4K4 appears to be linked to the response to environmental stress and cytokines such as tumor necrosis factor- $\alpha$ (TNF- $\alpha$ ). TNF- $\alpha$ is released in the microenvironment predominantly by infiltrating macrophages and participates in the chronic inflammation associated with PDA $(10,11)$.

The aim of the present study was to analyze MAP4K4 expression at the mRNA and protein level in surgical specimens from PDA patients. We examined whether MAP4K4 expression could differentiate PDA from chronic pancreatitis (CP) and if it is associated with clinical outcome.

\section{METHODS}

\section{Patients}

The study included 58 patients with PDA and 9 with chronic pancreatitis, who underwent pancreatic resection at the Center of Digestive Disease and Liver Transplantation of Fundeni Clinical Institute, Bucharest, Romania, between 2003-2008. None of the patients received neoadjuvant therapy. All patients provided informed, written consent for the use of their samples, and the study was approved by the Ethics Committee of Fundeni Clinical Institute Bucharest, Romania, in accordance with ethical standards included in the current revision of the Helsinki Declaration. Clinicopathologic and follow-up data were gathered retrospectively for each case from the patient's medical records. Post-operative survival was measured from the day of surgery to death or the date of last follow-up visit.

\section{Pancreatic tissues specimens}

Tissue samples were collected at the time of surgery from all PDA and CP patients. Each specimen was cut in at least two pieces and one was stored at $-80^{\circ} \mathrm{C}$ and one was formalin-fixed and paraffin-embedded. The gross pathological features analyzed were the size of the tumor, presence or absence of tumor necrosis and regional lymph involvement. All patient samples were coded to protect patients' confidentiality. The diagnosis, histological typing, grading and staging were independently evaluated by two experienced gastrointestinal pathologists (V.H. and C.P.). The tumor node metastasis (TNM) staging was defined according to the International Union Against Cancer criteria (12).

\section{Immunohistochemical analysis}

The MAP4K4 protein expression was analyzed in PDA samples in intratumoral areas, peritumoral areas (junction area) and non-tumoral areas (normal tissue) by immunostaining. We used anti-MAP4K4 antibody (Sigma-Aldrich, Saint Louis, USA, catalog number HP008476) and DAKO Envision Dual Link as detection system, following the manufacturer's recommendations. High expression of MAP4K4 (MAP4K4-H) was defined as cytoplasmic staining of $\geq 10 \%$ of the tumor cells, and low expression of MAP4K4 (MAP4K4-L) was defined as cytoplasmic staining of $<10 \%$ of the tumor cells or no cytoplasmic staining, as previously reported $(13,14)$.

\section{RNA extraction and cDNA synthesis}

Total RNA was extracted from snap frozen pancreatic tissue specimens and PDA cells using the Tri Reagent $^{\text {TM }}$ (Sigma-Aldrich, USA). The concentration of each total RNA sample was measured with a Nanodrop ND-1000 spectrophotometer (Nanodrop Technologies, Wilmington, USA). RNA integrity was determined by capillary electrophoresis with an Agilent 2100 Bioanalyzer (Agilent, Santa Clara, USA), and the extracted RNA was accepted for experiments if the RNA integrity number was over 7.0. First strand CDNA synthesis was performed using MultiScribe ${ }^{\mathrm{TM}}$ reverse transcriptase and random primers (Applied Biosystems, USA) according to manufacturer indications.

\section{Quantitative RT-PCR}

The cDNA was analyzed by quantitative RT-PCR using an Applied Biosystems Sequence Detection System 7300 and TaqMan $^{\circledR}$ Gene Expression Assays Protocol (Applied Biosystems). For the amplification of the cDNA, $\operatorname{TaqMan}^{\circledR}$ gene expression assays with MAP4K4 predesigned primers and probe sets (ID Hs00377410_m1, Applied Biosystems) were used. All 58 PDA samples were analyzed in triplicate, against the reference gene 18S RNA. Gene expression levelswere assessed by analyzing threshold cycle (Ct) 
values for each sample. Gene expression levels were calculated for each gene using double normalization method $(\Delta \Delta \mathrm{Ct})$

\section{Statistical analysis}

Descriptive statistical measures, including the mean \pm standard deviation, median and range, were calculated. Data are presented as mean \pm SD unless otherwise specified; because the data distribution did not follow a Gaussian curve on preliminary statistical analysis, the comparisons between groups were performed using nonparametric significance tests (Mann-Whitney U test and Kruskal-Wallis test). The gene or protein expression of MAP4K4 was analyzed based on clinicopathologic split variables, including degree of differentiation, tumor size, tumor grade and lymph node invasion. In addition, correlations between different measurements were investigated using the Spearman's Rho correlation coefficient. Survival distributions were calculated using the Kaplan-Meier product-limit method and compared by log-rank test. Comparisons with a $p$ value of less than 0.05 were considered statistically significant. The effects of gene silencing, proliferation and migratory capacity were analyzed using Student t-test. All statistical analyses were performed with SPSS version 17.0 software (SPSS, Chicago, IL).

\section{RESULTS}

\section{Patient characteristics}

Patient demographics are listed in table 1. Our study included tissue from 58 patients with PDA ( 33 men and 25 women) with mean age at diagnosis 61.6 years (range, 43-77 years). The mean tumor diameter was $2.89 \mathrm{~cm}$ (range, 0.3-8 cm). According to the AJCCE classification, PDA was stage $I$ in 18 patients (31\%), stage II A in 7 patients (12\%), IIB in 26 patients (45\%) and stage III/IV in 7 patients (12\%). 32 (55\%) of PDA patients had lymph node metastases. As a control, we studied tissues from 9 patients (4 men and 5 women) with pathologically confirmed CP. The mean age at diagnosis for the CP group was 58 years (range: 45-79 years).

\section{MAP4K4 expression is higher in PDA and is associated with tumor grade}

We found a significantly higher mRNA MAP4K4 expression in PDA tissue compared to pancreatic tissue from CP patients (Mann Whitney test, $\mathrm{p} \leq 0.003$ )
Table 1 - Clinicopathologic characteristics of the PDA patients $(n=58)$

\begin{tabular}{|c|c|c|}
\hline & $\mathbf{N}$ & $\%$ \\
\hline \multicolumn{3}{|l|}{ Gender } \\
\hline Male & 33 & 57 \\
\hline Female & 25 & 43 \\
\hline \multicolumn{3}{|l|}{ Age at surgery (years) } \\
\hline $\begin{array}{l}\text { mean } \pm \text { SD } \\
\text { median (range) }\end{array}$ & $\begin{array}{c}61.6 \pm 8.2 \\
61(43-77)\end{array}$ & - \\
\hline \multicolumn{3}{|l|}{ TNM stage } \\
\hline$|A+| B$ & 18 & 31 \\
\hline$\| A$ & 7 & 12 \\
\hline \|I B & 26 & 45 \\
\hline III + IV & 7 & 12 \\
\hline \multicolumn{3}{|l|}{ Grading } \\
\hline G1 & 33 & 57 \\
\hline G2 & 21 & 36 \\
\hline G3 & 4 & 7 \\
\hline \multicolumn{3}{|l|}{ Lymph node status } \\
\hline NO & 26 & 45 \\
\hline N1 & 32 & 55 \\
\hline \multicolumn{3}{|c|}{ Lymph node ratio $(\mathrm{N}=30)$} \\
\hline$<0.5$ & 25 & \\
\hline$\geq 0.5$ & 5 & \\
\hline \multicolumn{3}{|c|}{ Postop. Chemotherapy ( $\mathrm{N}=27)$} \\
\hline Yes & 19 & 70 \\
\hline No & 8 & 30 \\
\hline \multicolumn{3}{|l|}{ Tumor diameter } \\
\hline mean \pm SD & $2.89 \pm 1.4$ & - \\
\hline median (range) & $3(0.30-8)$ & \\
\hline \multicolumn{3}{|l|}{ Resection type } \\
\hline Ro & 55 & 95 \\
\hline $\mathrm{R} 1$ & 3 & 5 \\
\hline \multicolumn{3}{|l|}{ Diabetes $(\mathrm{N}=53)$} \\
\hline Yes & 13 & 24 \\
\hline No & 40 & 76 \\
\hline
\end{tabular}

Table 2 - MAP4K4 expression in PDA versus CP tissues

\begin{tabular}{lcc}
\hline & Median (range) & p-value \\
\hline $\mathrm{PDA}(\mathrm{N}=58)$ & $6.5(0.2-88.4)$ & 0.003 \\
\hline $\mathrm{CP}(\mathrm{N}=9)$ & $1.25(0.13-7.4)$ & \\
\hline
\end{tabular}

(table 2). Moreover, in univariate analyses, we found that MAP4K4 mRNA expression in PDA was significantly correlated with TNM stage ( $\mathrm{p} \leq 0.026$, Kruskal-Wallis test)(table 3). In addition, MAP4K4 protein expression (fig. 1) was statistically significant correlated with tumor grade (Spearman's Rho $=0.449, p=0.01$ ). Thus, the expression of the MAP4K4 protein appears to increase with PDA progression. 

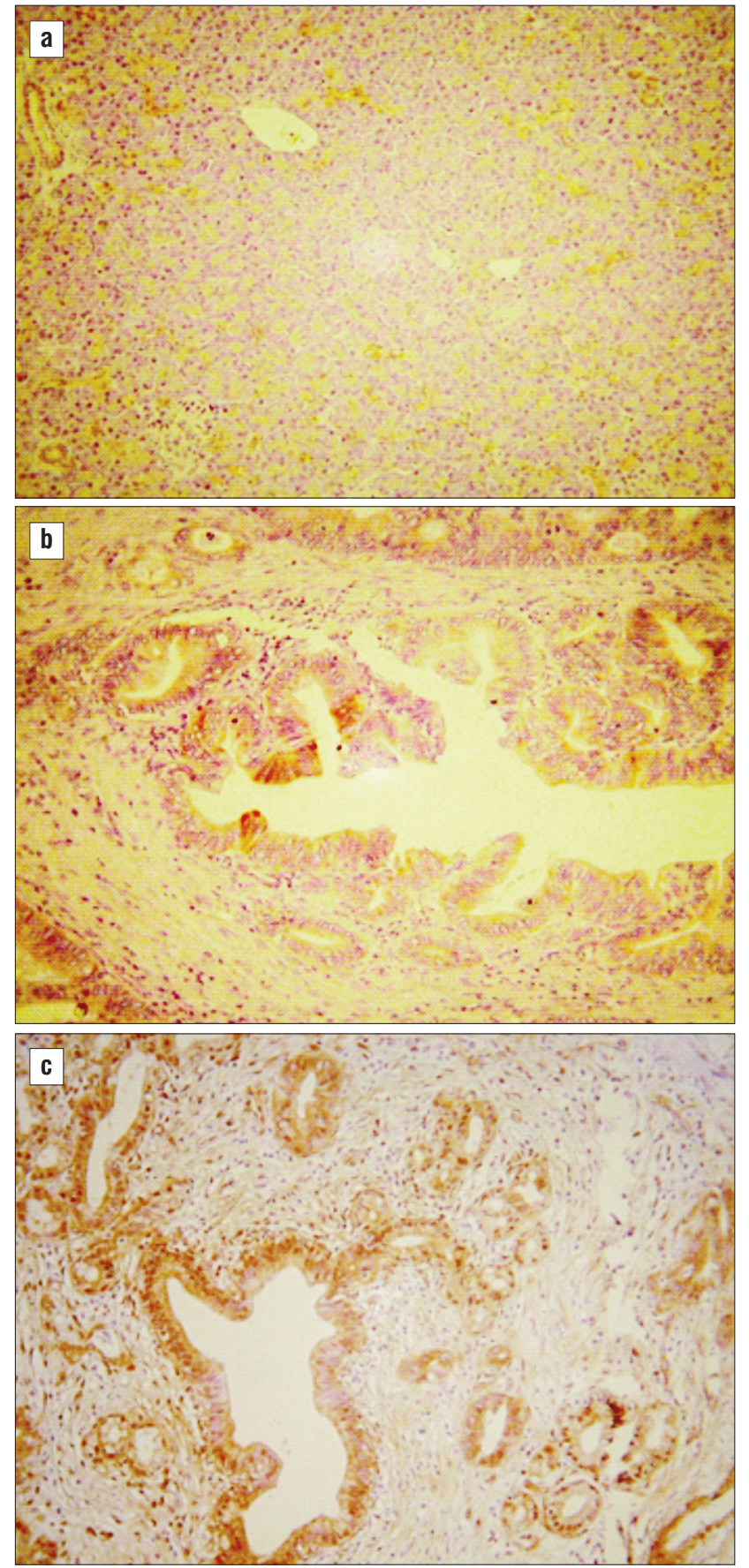

Figure 1 - Representative immunostaining for MAP4K4 in normal and neoplastic pancreatic tissues. a, Tumor-adjacent pancreatic tissue showing no detectable MAP4K4 expression. b, Focal expression of MAP4K4 in cell cytoplasm in CP. c, Strong cytoplasmic and nuclear staining for MAP4K4 in PDA tissue. Original magnification, $\mathrm{x} 100$

\section{MAP4K4 expression tends to associate with poor survival in $P D A$ patients}

All patients were followed up for an average of 18 months (range 2-90 months). Of the 58 PDA patients, five patients were alive at the census date. The Kaplan-
Table 3 - Correlation of MAP4K4 mRNA expression with clinicopathological factors

\begin{tabular}{|c|c|c|}
\hline Clinicopathological features & MAP4K4 & \\
\hline median (range) & p-value & \\
\hline \multicolumn{3}{|l|}{ Gender } \\
\hline Male & $5.76(0.2-88.4)$ & $0.39 *$ \\
\hline Female & $7.18(0.4-59.4)$ & \\
\hline \multicolumn{3}{|l|}{ TNM stage } \\
\hline $\mid A+I B$ & $6.26(0.2-36)$ & \\
\hline$\| A$ & $3.47(0.59-30.25)$ & $0.026^{\star \star}$ \\
\hline$\| \mathrm{B}$ & $5.37(0.43-88.4)$ & \\
\hline IV & $34.9(10-59.4)$ & \\
\hline \multicolumn{3}{|l|}{ Tumor grade } \\
\hline G1 & $7.18(0.33-88.4)$ & \\
\hline G2 & $5.34(0.2-34.9)$ & $0.28 * \star$ \\
\hline G3 & $28.5(2.78-36.03)$ & \\
\hline \multicolumn{3}{|l|}{$\mathrm{pN}$ stage } \\
\hline pNO & $6.26(0.2-37.8)$ & $0.32^{\star}$ \\
\hline pN1 & $10.6(0.4-88.4)$ & \\
\hline \multicolumn{3}{|l|}{ Lymph node ratio $(\mathrm{N}=30)$} \\
\hline$<0.5$ & $11.4(0.33-88.4)$ & $0.83^{\star}$ \\
\hline$\geq 0.5$ & $10.5(0.4-28)$ & \\
\hline \multicolumn{3}{|l|}{ Postop. Chemotherapy $(\mathrm{N}=27)$} \\
\hline Yes & $6.17(0.4-88.4)$ & $0.82^{\star}$ \\
\hline No & $11.9(1.18-29.3)$ & \\
\hline \multicolumn{3}{|l|}{ Resection type } \\
\hline Ro & $6.17(0.2-88.4)$ & $0.81^{\star-}$ \\
\hline $\mathrm{R} 1$ & $5.34(4.7-5.4)$ & \\
\hline \multicolumn{3}{|l|}{ Type I Diabetes $(\mathrm{N}=53)$} \\
\hline Yes & $6.72(0.3-59.4)$ & $0.61^{\star}$ \\
\hline No & $5.58(0.2-88.4)$ & \\
\hline
\end{tabular}

*Mann-Whitney test; **Kruskal-Wallis test

Meier survival distributions showed that PDA patients with high MAP4K4 protein expression tended to have shorter survival compared to those with low protein expression ( $p=0.072$, log rank test) (fig. 2). The median overall survival was 11 months for PDA patients whose tumors were MAP4K4-H ( $n=40)$, and 25 months for PDA patients whose tumors with MAP4K4-L $(n=13)$.

\section{DISCUSSION}

Recent studies have shown that MAP4K4 is increased in different types of human cancer tissue and cell lines $(4,15,16)$. We have previously shown that that MAP4K4 is over-expressed in PDA tissue using gene array (4). Here, we investigated the role and the prognostic significance of MAP4K4 in PDA patients and examined the role of MAP4K4 in PDA cells.

We first confirmed the overexpression of MAP4K4 in PDA both at the mRNA and protein levels compared to adjacent non-tumor pancreatic tissue. Moreover, we show that MAP4K4 expression increased with tumor 
Survival Functions

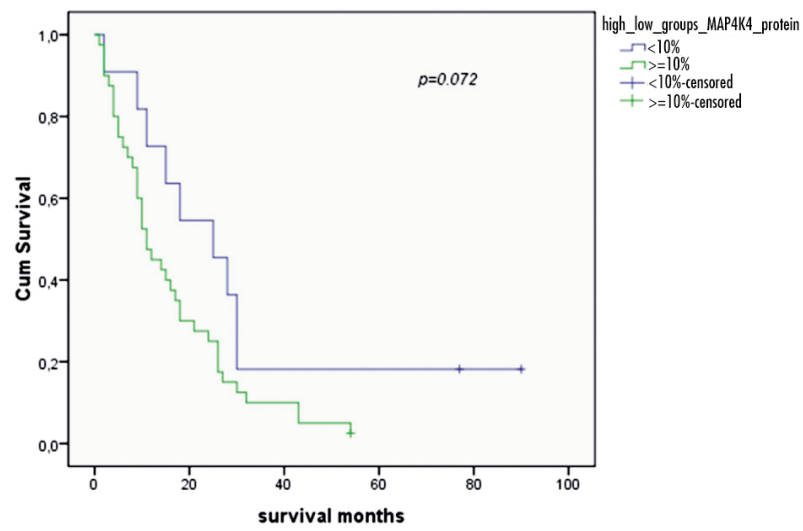

Figure 2 - Kaplan-Meier curves for overall survival by MAP4K4 protein expression

stage and may be associated with a poor survival in PDA patients. Our results are in agreement with previously reported data by Liang et al. that MAP4K4 expression is associated with poor overall and recurrence-free survival and is a prognostic factor for patients with stage II PDA (13).

The MAPK pathway has been previously involved PDA progression. Blocking the upstream receptor (EGFR) activation was the first targeted therapy approach that led to increased survival in PDA patients (17). Handra-Luca et al. suggested that MKK4 is directly related to high cell proliferation, and that tumor ERK1/2 and P38MAPK expression correlated to shorter postsurgical recurrence-free and overall survival rates. They reported that MKK4 expression was correlated with advances tumor stages N1 and T3 TNM, and with high $\mathrm{Ki}-67$ index, suggesting that MKK4 is involved in cell proliferation (18).

Despite increasing evidence that MAP4K4 is a poor prognostic factor in PDA, little is known about its function. The main activators of MAP4K4 are stressrelated factors and proinflammatory cytokines such as TNF- $\alpha$ (19). Indeed, we have recently reported that increase in blood circulating proinflammatory cytokines is a poor prognostic factor PDA patients (20). In other malignancies, it has been shown that MAP4K4 can directly activated JNK through TAK1, MKK4, and MKK7 (21). JNK family plays crucial roles in regulating responses to various stresses, inflammation, and apoptosis (22). MAP4K4 has also been reported to activate a number of other proteins, including kinases within the JAK/STAT pathway that sustain cell proliferation and angiogenesis (15). Based on data using silencing of the MAP4K4 expression in hepatocellular carcinoma, Liu et al. suggested that MAP4K4 is a key player in the progression of this cancer by increasing cell viability (14).

\section{CONCLUSION}

In conclusion, our data indicate that MAP4K4 expression is selectively upregulated in malignant versus chronically inflamed pancreatic tissues and its mRNAlevel directly correlates with tumor grade and with a poor outcome in PDA patients. The biological significance of MAP4K4 explored by knocking down its expression revealed that MAP4K4 appears to primarily mediate cell invasion. Collectively, these data suggest that MAP4K4 may be a biomarker and potentially a target for therapy in PDA. Further studies are necessary to investigate this hypothesis.

\section{Acknowledgements}

This study was supported by grants from National Authority for Scientific Research PN-II-PT-PCCA-201190 and PN-II-RU-TE-100/2010 and also a project financed from the European Social Fund and by the Romanian Government under the contract number POSDRU/89/1.5/S/60746.

\section{REFERENCE}

1. Jemal A, Bray F, Center MM, Ferlay J, Ward E, Forman D. Global cancer statistics. CA Cancer J Clin. 2011 March;61(2):69-90.

2. Plentz RR, Manns MP, Greten TF. Molecular therapy of pancreatic cancer. Minerva Endocrinol. 2010 March;35(1):27-33.

3. Schneider G, Siveke JT, Eckel F, Schmid RM. Pancreatic cancer: basic and clinical aspects. Gastroenterology. 2005 May;128(6): 1606-25.

4. Badea L, Herlea V, Dima SO, Dumitrascu T, Popescu I. Combined gene expression analysis of whole-tissue and microdissected pancreatic ductal adenocarcinoma identifies genes specifically overexpressed in tumor epithelia. Hepatogastroenterology. 2008 November; 55(88): 2016-27.

5. Lee TJ, Sartor 0, Luftig RB, Koochekpour S. Saposin C promotes survival and prevents apoptosis via PI3K/Akt-dependent pathway in prostate cancer cells. Mol Cancer. 2004 November 17;3:31.

6. Roux PP, Blenis J. ERK and p38 MAPK-activated protein kinases: a family of protein kinases with diverse biological functions. Microbiol Mol Biol Rev. 2004 June;68(2):320-44.

7. Sebolt-Leopold JS, Herrera R. Targeting the mitogen-activated protein kinase cascade to treat cancer. Nat Rev Cancer. 2004 December; 4(12):937-47.

8. Weston CR, Davis RJ. The JNK signal transduction pathway. Curr Opin Genet Dev. 2002 February;12(1):14-21.

9. Yao Z, Zhou G, Wang XS, Brown A, Diener K, Gan H, et al. A novel human STE20-related protein kinase, HGK, that specifically activates the c-Jun N-terminal kinase signaling pathway. J Biol Chem. 1999 January 22;274(4):2118-25.

10. Nathan C. Points of control in inflammation. Nature. 2002 December 19; 420(6917):846-52.

11. Pollard JW. Tumour-educated macrophages promote tumour progression and metastasis. Nat Rev Cancer. 2004 January;4(1):71-8.

12. American Joint Committee on Cancer. Pancreatic cancer staging. American Joint Committee on Cancer. Cancer Staging Manual. $6^{\text {th }}$ ed. 
Springer; 2002.

13. Liang JJ, Wang H, Rashid A, Tan TH, Hwang RF, Hamilton SR, et al. Expression of MAP4K4 is associated with worse prognosis in patients with stage II pancreatic ductal adenocarcinoma. Clin Cancer Res. 2008 November 1;14(21):7043-9.

14. Liu AW, Cai J, Zhao XL, Jiang TH, He TF, Fu HQ, et al. ShRNAtargeted MAP4K4 inhibits hepatocellular carcinoma growth. Clin Cancer Res. 2011 February 15;17(4):710-20.

15. Collins CS, Hong J, Sapinoso L, Zhou Y, Liu Z, Micklash K, et al. A small interfering RNA screen for modulators of tumor cell motility identifies MAP4K4 as a promigratory kinase. Proc Natl Acad Sci USA. 2006 March 7;103(10):3775-80.

16. Wright JH, Wang X, Manning G, LaMere BJ, Le P, Zhu S, et al. The STE20 kinase HGK is broadly expressed in human tumor cells and can modulate cellular transformation, invasion, and adhesion. Mol Cell Biol. 2003 March;23(6):2068-82.

17. Moore MJ, Goldstein D, Hamm J, Figer A, Hecht JR, Gallinger S, et al. Erlotinib plus gemcitabine compared with gemcitabine alone in patients with advanced pancreatic cancer: a phase III trial of the National Cancer Institute of Canada Clinical Trials Group. J Clin Oncol.
2007 May 20;25(15):1960-6.

18. Handra-Luca A, Lesty C, Hammel P, Sauvanet A, Rebours V, Martin A, et al. Biological and prognostic relevance of mitogen-activated protein kinases in pancreatic adenocarcinoma. Pancreas. 2012 April;41(3): 416-21.

19. Tesz GJ, Guilherme A, Guntur KV, Hubbard AC, Tang X, Chawla A, et al. Tumor necrosis factor alpha (TNFalpha) stimulates Map4k4 expression through TNFalpha receptor 1 signaling to c-Jun and activating transcription factor 2. J Biol Chem. 2007 July 6;282(27): 19302-12.

20. Dima S0, Tanase C, Albulescu R, Herlea V, Chivu-Economescu M, Purnichescu-Purtan R, et al. An exploratory study of inflammatory cytokines as prognostic biomarkers in patients with ductal pancreatic adeno-carcinoma. Pancreas. 2012 October;41(7):1001-7.

21. Favata MF, Horiuchi KY, Manos EJ, Daulerio AJ, Stradley DA, Feeser WS, et al. Identification of a novel inhibitor of mitogen-activated protein kinase kinase. J Biol Chem. 1998 July 17;273(29):18623-32.

22. Das M, Garlick DS, Greiner DL, Davis RJ. The role of JNK in the development of hepatocellular carcinoma. Genes Dev. 2011 March 15;25(6):634-45. 